\title{
Studies of particular languages
}

ENGLISH See also abstract 72-200

72-192 Allsop, R. What dictionary should West Indians use? The Fournal of Commonwealth Literature (Leeds), 6, 2 (1971), I33-43.

English-speaking Caribbean countries have two things in commonAfricanized populations and British-style education. Caribbean English has largely been ignored, especially by lexicographers. In the Dictionary of Famaican English only about one-sixth of the material corresponds with Standard British English usage. Caribbean words are numerous and in free circulation among literate Caribbeans. The absence of academic attention to Caribbean English contributes to cultural insecurity. A dictionary of Caribbean English usage is needed.

420 AFL ALG 972.9

72-193 Funk, Wolf-Peter. Adjectives with negative affixes in modern English and the problem of synonymy. Zeitschrift für Anglistik und Amerikanistik (Leipzig), 19, 4 (197I), $364-83$.

Suffixes function as class markers; prefixes cause only semantic change. A syntactic derivative can be regarded as the lexical equivalent of a corresponding negated relative clause. There are numerous derivatives from stems that are themselves syntactic derivatives. A semantic derivative, in the field of prefixal negation, is not the same thing. There are many such words which are not strict opposites but which occupy an intermediate position by being ambiguous even in definite contexts. Stems that express the idea of a single alternative tend to form contradictory opposites, while those that do not suggest such an idea but denote some specific quality tend to form contrary opposites. Semantic derivatives can be classified into contrary 
opposites, and contradictory opposites with a contrary tinge. Syntactic derivatives are derivational lexical equivalents of various types of relative clause.

[The author discusses in some detail negative affixes to adjectives and tabulates his conclusions. He then deals with lexical clashes caused by alternative derivation from the same stem. He describes two main modes of formation, intentional and unintentional. $\mathrm{He}$ distinguishes between pairs of the same and of different semantic structure.]

The negative prefixes are synonymous in so far as each may denote contradictory opposition and also (except for non-) contrary opposition. They are not synonymous in so far as they show different degrees of inclination for the various semantic structures, different combinative powers as to the origin of stems, and different fields of application as regards stylistic layers. [The author summarizes points made about in-, un-, dis- and non-.] With all affixes there are several alternative derivatives with no semantic distinction. Deverbal adjectives are derived on a syntactic basis largely by the prefix un-. Ordinary (non-deverbal) adjectives are subject to semantic selection. Adjectival stems with a strongly characterizing element tend to be derived by un-. Stems with a classifying meaning tend to be negatived by non-. Stems including both aspects are frequently subject to alternative derivation by $u n$ - and $n o n$ -

420 ADF AKD ALR

72-194 Jacobsson, Bengt. A note on the classification of relative nominal clauses in English. Moderna Språk (Saltsjö-Duvnäs), 65, 4 (197r), 312-22.

Nominal clauses introduced by who and what cannot be discussed in terms of a simple division into relative and interrogative. They are situated along a scale ranging from definiteness to indefiniteness, and who clauses become less probable as we approach the definite end of the scale. [The author briefly surveys what the grammars say about what and who in nominal clauses. He gives examples showing that certain uses of nominal who clauses are fairly frequent in modern literature.] A particular element in a sentence can be 
made prominent in various ways. [The author discusses 'cleft' sentences, especially those which contain a first or second person singular pronoun in the introductory phrase. He gives many examples of 'unorthodox third person concord'.]

A pronoun in the introductory phrase of a cleft sentence may be governed by the verb in the relative clause, and the choice of verb in the relative clause may be influenced by the pronoun in the introductory phrase.

420 ADN AKN

72-195 Meyer, Hans Joachim. Die Richtungsvarianten von 'up' im Kontext mit Verben. [The directional varieties of 'up' in context with verbs.] Zeitschrift für Anglistik und Amerikanistik (Leipzig), 19, 4 (1971), 387-408.

With illustrations from modern English plays and novels the prepositional and non-prepositional form of $u p$ is studied and traditional grammar and transformational analyses are seen to agree on its treatment. An analysis is made of $u p$ as a source of information on place and direction. Three notions of height, vertical position and distance are isolated. The contexts in which such information can be provided are examined and special combinations with turn, show, crop, draw, pull and others are studied. $U p$ is examined as an indicator of direction. There are two groups of 'verb and particle' giving durative and non-durative meanings. In conclusion some consideration is given to the problem of whether difference in meaning corresponds to the syntactic boundary drawn between preposition and particle.

420 ALD

72-196 Pierce, Joe E. A look at the so-called past tenses and participial forms of English verbs. Linguistics (The Hague), 7r (1971), 87-94.

The old terms of English structure such as participle, passive and active voice, animate and inanimate nouns need to be re-evaluated. This can only be done by taking one item of grammar at a time, studying it in a corpus, and then generalizing from the examples 
studied. The phenomenon of so-called participles, past and present, is investigated. The study is based on a corpus of 6,000 words. Analysis of the past participles revealed a certain number of them as purely descriptive without any verbal function. There is no evidence that -ing or -ed always mark the progressive forms or past forms. Specifics of time and progression are determined by the sequence of morphemes, not the morphemes themselves.

420 ADN AK

72-197 Sears, Donald A. The noun adjuncts of modern English. Linguistics (The Hague), 72 (1971), 31-60.

Modern technical writing in all fields involves the expression of relationships which may be difficult for those whose primary training lies outside language and composition work. A sample report from the field of space research and engineering provides data for this study. The most frequently occurring feature was found to be the multiple noun adjunct used as an idea-compressing device to shorten the number of words required in making a report. This dominant characteristic of technical prose is also extended into general prose and is therefore analysed in detail. Ten features are studied: the uninflected form of adjuncts; compound adjuncts; phrasal adjuncts; the reverse order of adjuncts; adjective position; analysis of head words; proper nouns as adjuncts; acronyms as adjuncts; determiners and adjectives with adjuncts; and the possible ambiguity of adjunct phrases.

420 ADN ANG

\section{FRENCH See also abstract 72-183}

72-198 Dye, Omar A. The effects of translation on readability. Language and Speech (Teddington), 14, 4 (1971), 392-7.

This study aims to show the change in readability of French passages as a result of translation into English. Fourteen French works, ranging in time from Marivaux to De Gaulle, were paired with English translations and the R. F. Flesch 'new readability yardstick' 
(7. Appl. psychol. 32, 221) was used on five roo-word passages selected at random from each of the fourteen works. The Flesch Reading Ease scores increased for the English translations by a mean of 9.7 per cent.

Comparisons of two English translations of the same French original texts (eight in all) showed very few differences in the work of different translators. It is admitted that measurements based on English may indicate difficulty of both French and English passages to English-speaking people but may not measure the difficulty of either to a Frenchman. The conclusion reached is a confirmation of the view that readability measures difficulty of style.

440 AG ARG

72-199 Porquet, André. Une réforme de l'orthographe est-elle possible? [Is a reform of spelling possible?] L'enseignement du Français aux Etrangers (Paris), 198 (1971), 2-3.

Through suspicion of the young and fear of the newer teaching methods, many refuse even to formulate the question of the possibility of reform. However, in forty years language communication has shifted its emphasis from the written to the largely audio-visual. Difficulties of spelling take up time better spent on useful knowledge of greater world concern. The fossilization of French spelling is in large measure due to the timidity of officialdom when confronted with the vast project of reform, to the lack of unanimity among the reformers and to their aesthetic or snobbish recoil from the results which their logic approves. [Examples of inconsistency are given.]

440 ASM

\section{GERMAN}

72-200 Helbig, Gerhard. Die Negation 'nicht' in der deutschen Gegenwartssprache. [The negative 'nicht' in present-day German.] Glottodidactica (Poznan), 5 (I97I), 51-68.

There are two questions to be answered: first, whether the rules for placing nicht can be built up on the traditional concepts of sentence 
components, and secondly, whether a body of rules can be based on the difference in principle between the negation of the sentence and the negation of a sentence component (or word). Rules or indications given in textbooks such as Schulz-Griesbach, Jung and Glinz do not adequately represent current practice. Specialist articles by Bratu, Weiss and Mattausch give differing interpretations of the facts.

The work of Klima on negation in English and of Hartung and Stickel on negation in German is considered and this leads to a discussion of negation in generative grammar and deep structure, and of the influence of valency. Twenty 'theses' are set out, and eventually fifteen rules are formulated for placing nicht in present-day German. Each rule is illustrated by at least one example.

430 AKT (420)

\section{RUSSIAN}

72-201 McGranahan, William J. 'B' in phrasal and complex prepositions in scientific Russian. Slavic and East European Fournal (Madison, Wisconsin), 15, 3 (197r), 332-8.

As Russian scientific jargon is similar to American professional and technical writing in that it often uses a two- or three-word phrase where a basic preposition would serve, some phrases of this sort are investigated [the terms 'preposition' and 'word' are defined and also the descriptions 'phrasal', 'complex' and 'determined']. Statistics and examples of usage are given.

491.7 ALD

\section{2-202 Shapiro, Michael. Markedness and Russian stress. Linguistics (The Hague), 72 (1971), 6I-77.}

Research to date has provided a clear descriptive picture of Russian stress, but has failed to show the motivation of the data of stress and no analysis ties the rules of stress and stress mobility to the grammatical and semantic categories underlying the language as a whole. The function of Russian stress has also to be defined and this article attempts to show that a functional system exists and to 
demonstrate that aspect of the system which pertains to substantives. The conclusion is reached that the mobile stress of Russian substantives is in an iconic relationship to the synthetic markedness values which underlie the central cases of the Russian declensional system.

491.7 ADN AJP

72-203 Zemskaya, Ye. A. Русская разговорная речь. [Russian conversational speech.] Вопросы языкознания (Moscow), 5 (1971), 69-80.

'Conversational speech' is used here to describe free, spontaneous expression by speakers using literary Russian which has a complete linguistic system. ('Conversational speech', if defined as including colloquialisms and dialect, has no unified system.) As compared with written (or codified) literary Russian, conversational speech uses different resources and even where the two areas overlap there is a significantly different functional load. Extralinguistic factors naturally play an important role in conversational utterances: situational elements affect communication; gestures, mimicry and intonation play their part, as well as the fact that utterances are spontaneous and their flow cannot easily be reversed. It is in the field of phonology that the most obvious differences occur between the two levels of language [examples]. Morphology shows interesting contrasts in the usage of the verb, or dynamic marker, and the adjective, or static marker [examples]. In syntax, Russian conversational speech is distinguished by brevity of form and often by juxtapositions of elements between which morphological links remain unexpressed because extralinguistic factors supply the missing information. Word order frequently diverges widely from what would appear normal in written language [examples]. Some of the most interesting usages in conversational Russian occur in the field of lexis where speakers often resort to compound descriptive nominations [examples given].

491.7 ADN 


\section{OTHER NATIONAL LANGUAGES}

72-204 Gage, William W. The African language picture. Linguistic Reporter (Washington, DC), I3, 3 (I97I), I 5-27.

Figures are given to indicate the extent to which various languages are used as official languages in the forty-nine primary political divisions in the continent of Africa and its ten neighbouring insular political units. Details are also given of the use of the principal vernacular languages in the Niger-Congo and the Afro-Asiatic family groups. How these languages function is considered in the context of broad language zones comprising countries and groups of countries where a reasonably coherent pattern is evident in the general language situation. [Ten language zones are discussed.] Vernacular languages, such as Swahili, spoken over a wide area, play an extremely important role as 'trade' languages. [Approximate figures are given for the number of second language users of the principal indigenous 'trade' languages.]

Prospects for the development of a pan-African second language are not bright. Both Arabic and Swahili, obvious contenders, have disadvantages which militate against their adoption for this purpose, although either is likely to spread as a regional lingua franca, as are pidgin English, Mandekan, chiNyanja and Wolof. Taking into consideration the number of their speakers and their social importance, sixteen languages (led by Contemporary Standard Arabic, Colloquial Cairo Arabic and Swahili) seem to be those deserving most attention in programmes of African studies.

496 AFL 960

72-205 Wong, Hoy-kee. The development of a national language in Indonesia and Malaysia. Comparative Education (Oxford), 7, 2 (1971), 73-80.

National languages are increasingly used at all educational levels in Indonesia and Malaysia to unify their multiracial populations. The problems of this development are described in detail. 